\title{
Commentary: If you want to make everyone happy, sell ice cream! Can faster sometimes mean better?
}

\author{
Pierre-Emmanuel Noly, $\mathrm{MD}, \mathrm{PhD},{ }^{\mathrm{a}}$ and Simon Maltais, $\mathrm{MD}, \mathrm{PhD}^{\mathrm{b}}$
}

\footnotetext{
From the a Department of Cardiac Surgery, Montreal Heart Institute, Montréal, Québec, Canada; and ${ }^{\mathrm{b}}$ Department of Cardiac Surgery, Centre Hospitalié de l'Université de Montréal, Montréal, Québec, Canada.

Disclosures: Authors have nothing to disclose with regard to commercial support.

Received for publication March 8, 2019; accepted for publication March 11,2019; available ahead of print April 24, 2019.

Address for reprints: Simon Maltais, MD, PhD, Cardiac Surgery, CHUM, Pavillon E (PEA) 1000, Rue SaintDenis 13e Étage, Porte 1307, Montréal, Québec H2X 0C1, Canada (E-mail: simon.maltais.chum@ssss. gouv.qc.ca).

J Thorac Cardiovasc Surg 2020;159:445-10

$0022-5223 / \$ 36.00$

Copyright (C) 2019 by The American Association for Thoracic Surgery

https://doi.org/10.1016/j.jtcvs.2019.03.020
}

In this issue of the Journal, D'Onofrio and colleagues ${ }^{1}$ compared early outcomes after aortic valve replacement (AVR) with the Perceval-S (Livanova, London, UK) and the Intuity (Edwards Lifesciences, Irvine, Calif) bioprostheses. After a propensity-matching analysis of 911 "all comers" patients (Perceval-S, $\mathrm{n}=349$; Intuity, $\mathrm{n}=562$ ), they compared 2 groups of 117 patients. The choice of the device was left to the discretion of the surgeon and was not based on well-defined criteria. In the matched analysis, 114 patients $(48 \%)$ underwent isolated AVR, and only 56 $(23 \%)$ had a minimally invasive approach. The mean age and the mean Society of Thoracic Surgeons score were roughly 78 years and $3.5 \%$ in both groups. D'Onofrio and colleagues $^{1}$ reported shorter cardiopulmonary bypass and aortic crossclamp time with the Perceval-S, without any difference in clinical outcomes. The rates of the 2 devicespecific complications (permanent pacemaker implantation, $6 \%$; moderate or severe paravalvular leak, $1.7 \%$ ) are consistent with previous publications. Finally, they reported slightly lower gradients in the Intuity group early after the surgery.

Although this study is the largest available comparison of these 2 devices, it does not provide any advice or help in choosing the right prosthesis for the right patient. If both Perceval-S and Intuity bioprostheses facilitate minimally invasive AVR, we might tailor their use according to the specific patient's characteristics. Because of its rapid and friendly-user delivery system, the Perceval-S is usually privileged in older patients, with severe aortic calcifications and higher operative risk. For the same ease of use, some surgeons implant these valves with a less invasive technique. Because the Intuity valve is supposed to have equivalent durability to the Carpentier-Edwards Perimount Magna Ease, this device is more likely to be used in younger patients. Despite good midterm results for both Perceval-S and Intuity prostheses, ${ }^{2}$ long-term durability of theses bioprostheses is still unknown. Although their use could provide benefits for patients with a higher risk profile to

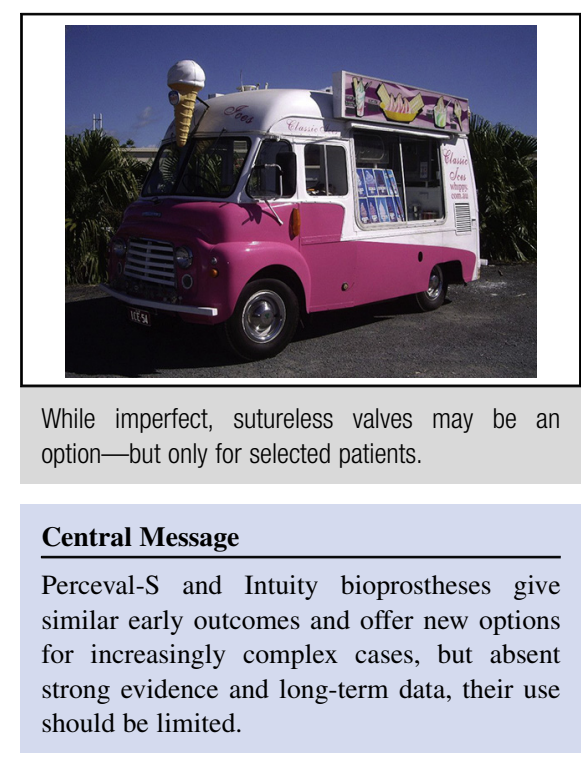

See Article page 432 .

minimize cardiopulmonary bypass and crossclamp times, the higher risk of pacemaker implantation after AVR remains a clear barrier to widespread use, especially for younger and healthier patients.

As pointed out by Carrier and associates, ${ }^{3}$ there is a lack of strong evidence regarding the clinical benefits of these valves. Sutureless or rapid-deployment valves, as well as automatic knotting systems, are perhaps only new options to reduce operative time. The invasive nature of these valves and the surgical approach they require do NOT allow us to make a fair comparison with transcatheter valves. Is a decrease of 15 minutes of cardiopulmonary bypass time truly a game changer in the postoperative course, especially in the context of single AVR in patient at low or intermediate risk? Is the benefit of these device worth their increased cost or their higher risk of complications, such as pacemaker implantation? A significant proportion of the patients included in the unmatched analysis might correspond to patients at intermediate operative risk. These patients would probably now be candidate for a newer generation transcatheter AVR procedure, which has proved to be safe and reliable. One could then ask the real question: Is transcatheter AVR superior to minimally invasive AVR with a Perceval-S or Intuity valve in patients with intermediate or high operative risk? Although these valves offer new 
options, we need to assess these devices carefully and in the context of all patients' preoperative factors.

\section{References}

1. D’Onofrio A, Salizzoni S, Filippini C, Tessari C, Bagozzi L, Messina A, et al Surgical aortic valve replacement with new generation bioprostheses: sutureless versus rapid-deployment. J Thorac Cardiovasc Surg. 2020;159: 432-42.e1.

2. Sponga S, Barbera MD, Pavoni D, Lechiancole A, Mazzaro E, Valente M, et al. Ten-year results of the Freedom Solo stentless heart valve: excellent haemodynamics but progressive valve dysfunction in the long term. Interact Cardiovasc Thorac Surg. 2017:24:663-9.

3. Carrier M, Bouchard D. Rapid-deployment bioprosthetic aortic valve replacement; there is a flag on the field! J Thorac Cardiovasc Surg. 2018;155:2400-1. 